\title{
Improving Organizational Learning: Defining Units of Learning from Social Tools
}

\author{
André Luís Andrade MENOLLI ${ }^{1,2}$, Sheila REINEHR ${ }^{1}$, \\ Andreia MALUCELLI ${ }^{1}$ \\ ${ }^{1}$ Polytechnic School, Postgraduate Program in Computer Science \\ Pontificia Universidade Católica do Paraná, Curitiba, Brazil \\ ${ }^{2}$ Computer Science Department, Universidade Estadual do Norte do Paraná, Bandeirantes, Brazil \\ e-mail:menolli@uenp.edu.br,sheila.reinehr@pucpr.br,malu@ppgia.pucpr.br
}

Received: April 2013

\begin{abstract}
New technologies, such as social networks, wikis, blogs and other social tools, enable collaborative work and are important facilitators of the social learning process. Many companies are using these types of tools as substitutes for their intranets, especially software development companies. However, the content generated by these tools in many cases is not appropriately organized. Therefore, this information is often not accessed by the company. Learning objects and units of learning are two e-learning concepts that allow content to be organized in a suitable sequence, thus improving its learning and reuse. Therefore, an approach is proposed to generate learning objects and units of learning from social tools in order to organize information for easy reuse. To evaluate the proposed approach, an experimental study was conducted and subjected to discursive textual analysis. The results show that the approach is viable for improving organizational learning in software development teams. Furthermore, the approach is efficient, especially in terms of the acquisition of new knowledge. It also helps to maintain the organizational pattern and minimize the reinvention of solutions and the repetition of errors.
\end{abstract}

Keywords: improving organizational learning, knowledge management, learning objects, unit of learning.

\section{Introduction}

Knowledge is an essential property for companies in contemporary economics. More than ever before, knowledge has been spreading among individuals, teams and organizations. Thus, the capacity to create, acquire, integrate, implement and disseminate knowledge has emerged as a fundamental competence for organizations in general (Takeishi, 2002) (Teece et al., 1997). To be successful, companies not only must explore current knowledge but must also continuously invest in the search for new knowledge as a strategic option for future decisions and as a way of developing a competitive edge (Sambamurth et al., 2003).

To create knowledge and help to improve organizational learning, a new trend concerning knowledge enablement (a set of activities that positively affect knowledge creation) in organizations, is emerging under the name of Enterprise 2.0 (Capuano et al., 
2010) which is defined by McAfee (McAfee, 2006) as the Emergent Social Software Platforms within companies. These emergent social software platforms are based on social tools, or Web 2.0 tools, such as social networks, wikis and blogs, and these tools mainly facilitate the communication among people. These new technologies and social environments help learning to take place socially, with people creating and sharing knowledge dynamically (Vassileva, 2009).

Nevertheless, although most social tools provide an efficient way to collaborate and create knowledge, they do not provide the means to achieve the required characteristics for social learning to occur satisfactorily.

Therefore, besides social tools, other mechanisms are required for social learning to occur within organizations. One way to organize information, facilitating search, evaluation and reuse, is to use learning objects (LO) and units of learning (UOL). A LO is defined as any independent digital or non-digital entity that may be reused in several teaching contexts (IEEE, 2002) (Polsani, 2004). Furthermore, a UOL can be seen as a general name for a course, a workshop or a lesson that can be instantiated and reused many times by different people and in different settings in an online environment (Koper et al., 2004). Normally, a UOL is defined by a learning design, which is an application of a pedagogical model for a specific learning objective, target group and a specific context or knowledge domain (Koper et al., 2004).

Thus, it cannot be guaranteed that the content created by social tools will help to promote organizational learning. However, the content produced by social tools within companies can be better organized, thus helping to promote organizational learning.

Consequently, an approach is proposed to organize the content generated using social tools in learning objects and later, using a learning design defined by an expert, create units of learning, using semantic technologies. In this way, knowledge can be organized didactically and instructionally, and be contextualized in specific domains so that it can be reused and made easily available whenever necessary. Moreover, in order to confirm the feasibility of this approach, an experiment was performed with software development teams. This experiment shows that the use of units of learning in software development teams can help to improve organizational learning and assist team members in the execution of some tasks.

The remaining sections of the paper are organized as follows: Section 2 contains the related works; Section 3 describes the approach to generate units of learning from social tools; Section 4 explains the experiment; Section 5 presents the results of the analyses; Section 6 presents the discussion and the paper is concluded in Section 7.

\section{Related works}

In recent years, organizations have begun to place more value on the experience and knowhow of their employees, i.e., their knowledge (Davenport and Prusak, 1998). Therefore, it has become a challenge to develop and implement processes that generate, store, organize, disseminate and apply the knowledge produced and used in a company in such a way that it can be systematically and reliably accessed by the organizational community. 
To this end, a concept that can help the management of organizational processes is organizational learning (Senge et al., 1994) (Ali et al., 2002). However, for a company applying organizational learning concepts, it is necessary to use knowledge generated by its members systematically and reliably (Menolli et al., 2011).

In recent years, resources such as wikis, blogs and social networks have been used as substitutes for intranets within companies (Carreras et al., 2011). Thus, several works are focusing on social tools to improve organizational learning. However, although there are many social resources, wikis are more prominent, and there are many researches exploring the potential of wikis to help the learning process.

For instance, (Lykourentzou et al., 2010) proposes a wiki that every time that an article is added, a novel expert peer matching algorithm (EPM), searches the human network of the organization to select the most appropriate peer employee to improve the quality of the article. Another study focusing on wikis (Dantas and Farias, 2010), presents an architecture using ontology as metadata to contextualize user search for information. The study presented by (Tseng and Huang, 2011) examines the content, technical and social values of Wikipedia to explore its influence on knowledge sharing and job performance. Finally, (Hadjerrouit, 2012) explores technical and pedagogical usability issues of collaborative learning with wikis.

However, none of the studies mentioned above uses the LO or UOL concept. Normally, LO and UOL studies are oriented to e-learning environments, for example (Leung and $\mathrm{Li}, 2007$ ), and they are not generally applied to research on companies. Furthermore, studies attempting to develop learning objects or units of learning automatically or semiautomatically are focused on the educational field, for instance, (Zouq and Nkambou, 2009), which introduces an approach that allows the accumulation of existing pedagogical resources, creating the first content metadata based on text mining and natural language processing, to develop learning objects dynamically.

Thus, the present study proposes organizing the contents generated by social tools in LOs and UOLs to make it possible to organize these contents in an adequate sequence, improving their learning and reuse. Moreover, the proposal also includes investigating whether this organization can help the learning of members of software development teams, thus aiding the promotion of organizational learning. In the following section, the proposed approach is presented.

\section{Proposed approach}

The proposed approach aims to generate units of learning from existing content in social tools. This approach is divided into two parts; the first defines learning objects from social tools, and the second generates the content packages of the units of learning. The first part of the approach was proposed by (Menolli et al., 2012a), and is shown in Fig. 1.

In the approach presented in Fig. 1, users first introduce content in the social tool. From the content inserted in the tool, an information retrieval component is used in order to extract and classify attributes according to the Ontology for Organizational Learning 


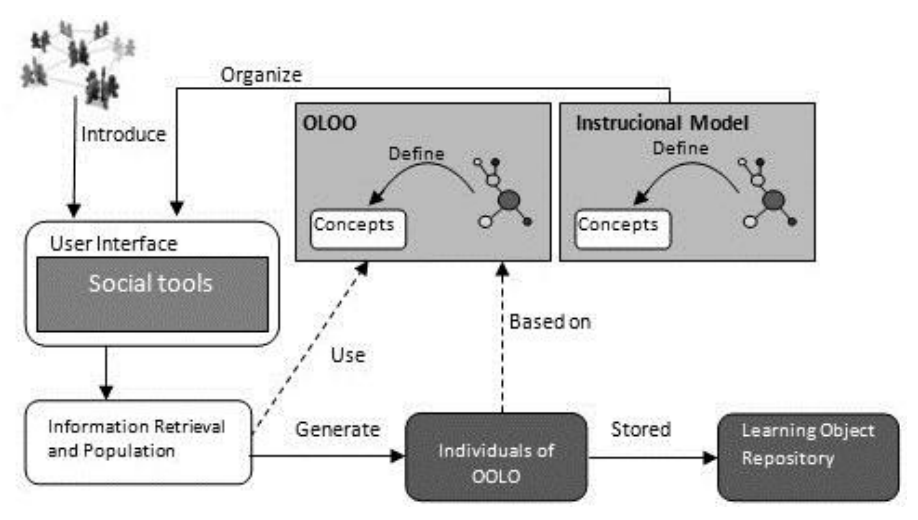

Fig. 1. Schema to generate learning objects from social tools by (Menolli et al., 2012a).

Objects (OOLO) (Menolli et al., 2012b), and the population component generates individuals in the Organizational Learning Object (OLO) format. These individuals are stored in a repository (Menolli et al., 2012a).

Therefore, using the learning objects generated, the purpose to improve the (Menolli et al., 2012a), approach, aiming to generate not only learning objects, but also courses, in order to promote a gain in the learning of the staff within companies. Fig. 2 shows the second part of the approach, the schema to generate units of learning semi-automatically from social content.

The schema presented in Fig. 2 is composed of three main components: (i) Learning Design Schema, defined by the domain expert by whom the unit of learning will be created; (ii) Learning Object Repository, a repository with all learning objects generated from social tools; and (iii) Unit of Learning Generator, the component responsible for searching in the Learning Object Repository for Learning Objects resources to create the unit of learning. Each one of these components is described in detail in the following sections.

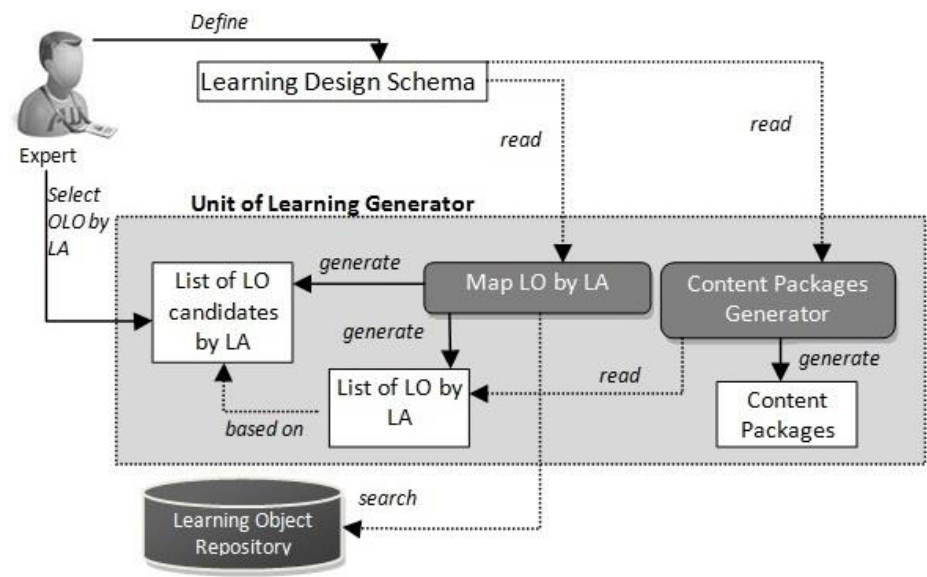

Fig. 2. Schema to generate units of learning from social tool. 


\section{A. Learning Design Schema}

The Learning Design Schema is adapted from IMS Learning Design (IMS LD). The IMS LD specification is a meta-language that describes all the elements of the design of a teaching-learning process, and drawn up by the IMS/LDWG work group (IMS, 2003). IMS LD describes a method that is made up of a number of activities conducted by both learner and staff in order to achieve some learning objectives (Amorim et al., 2006).

An expert within the company must define the Learning Design Schema manually. The expert is responsible for defining both the course content as the sequence of content. In this study, an adaptation of the schema of learning design schema was used (IMS, 2003), and the structure is presented in Fig. 3.

\section{B. Learning Object Repository}

The Learning Object Repository contains all learning objects generated by the schema presented in Fig. 1. This repository is an ontology called Ontology for Organizational Learning Objects (OOLO) (Menolli et al., 2012b), and this ontology is based on the IEEE LOM standard (IEEE, 2002).

Therefore, from the content inserted into the social tools, an information retrieval component is used in order to extract and classify attributes according to the OOLO. From the attributes extracted, the component generates individuals in the Organizational Learning Object (OLO) format and populates the OOLO with the individuals.

\section{Unit of Learning Generator}

The Unit of Learning Generator is the gray box in Fig. 2. This component is composed of other five elements, which are:

- Search LO by LA: this component reads the Learning Design Schema and at the Learning Object Repository discovers the learning objects, which correspond to

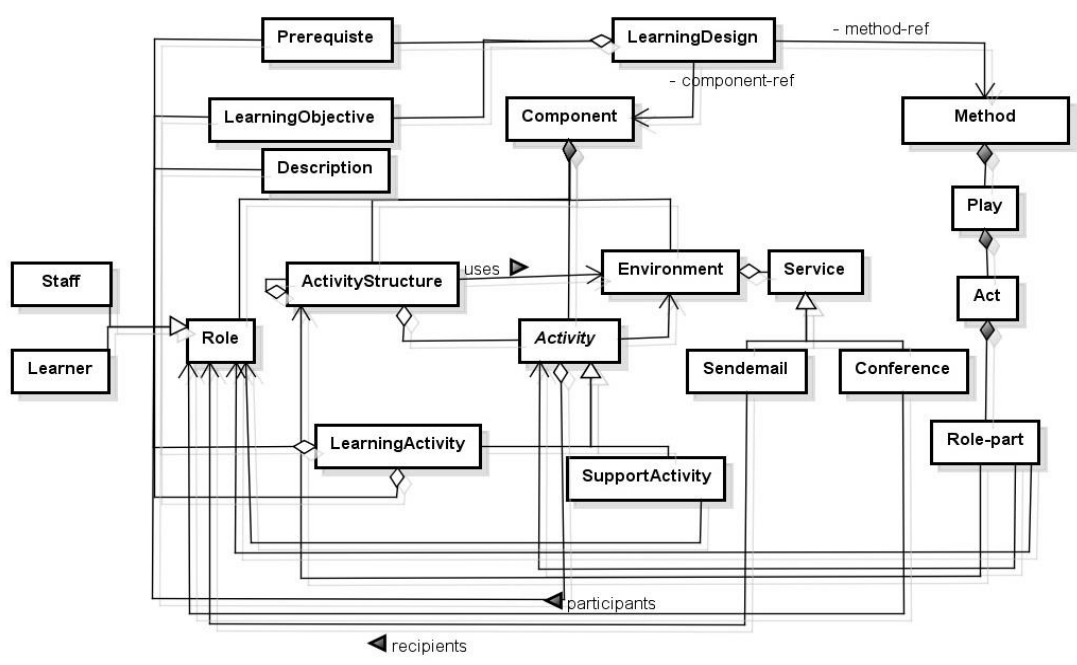

Fig. 3. Learning Design Schema Structure. Adapted from (IMS, 2003). 
Learning Activities (LA), described in the Learning Design Schema, generating a list of learning object candidates for each learning activity.

- List of LO candidates by LA: a list of learning objects that are possible resources for each learning activity. From this, for each learning activity, the expert chooses the appropriate learning object, as the corresponding resource for the learning activity.

- Content Packages Generator: using the Learning Design Schema, and the list of LO by LA, this component generates a structure of a course for each role-part presented in the Learning Design Schema. The courses are created as content packages, and their structure is related to the activity structure or learning activity defined for each role-part.

- Content Packages: these are the physical structure of the courses. A unit of learning can have more than one Content Package. The IMS Content Packaging Specification describes how digital resources can be organized into logical units of learning known as content packages (IMS, 2004).

As result, the proposed approach enables the content inserted into the social tool as learning objects to be organized. This facilitates the reuse of content and makes it possible to use the content in e-learning environments. Furthermore, using a semi-supervised approach, any expert can easily create units of learning, organizing the material produced within a company into modules that are didactically planned and contextualized in specific domains. This supports a better reuse of information and helps new team members to understand routines or organizational practices, thus promoting the learning organization.

\section{Experiment}

To assess the approach, an experiment was proposed. The main purpose of the experiment was to evaluate how the units of learning can help members of a software development team by focusing on improvements to existing software. Therefore, its applicability, conditions and possible restrictions were evaluated. Furthermore, the results were analyzed in order to evaluate the benefits and problems of the proposal.

As learning objects, in our approach, is a required step to generate units of learning and the proposal of (Menolli et al., 2012a) generates the learning object from wiki tools, this tool was used in our experiment. Therefore, pages from Wikipedia and a private wiki were extracted and organized into learning objects. From these objects units of learning, such as a course, were generated. These courses have the content and sequence defined by a domain expert. The intention was to analyze the impact that these materials, built using the expert's definitions, have on members of a software development team.

\section{A. Experimental Method}

This is an experimental study, which aims to collect data in a controlled environment to confirm or deny a hypothesis. The experimental method considers the proposal and evaluation of the model with experimental studies (Basili, 1996). 
In this experiment, the experimental strategy was chosen using a controlled experiment in a small object of study. Therefore, the experiment was classified according to (Basili, 1996) as it was:

- a descriptive study, as there may be patterns in the data but the relationship among the variables has not been examined;

- in vitro, because it is in the laboratory, under controlled conditions and therefore a controlled community was used;

- performed on novices, which are students with little experience in the study domain and

- an observational study, since there was no treatment or controlled variables.

In the next sections, the phases of the experimental study are described.

\section{B. Definition of Objectives}

To evaluate whether the material generated by social tools in units of learning can help software developers focusing on improvements in existing software.

\section{Planning}

The planning phase was divided into four parts. Each part is described in the following subsections.

1) Definition of Hypotheses: to guide the research three hypotheses were established based on the main goal of this experiment, which are described below:

- H1: developers, who have access to the units of learning, solve the required tasks faster than those who do not have access.

- H2: developers, who have access to the unit of learning, solve the required tasks according to the organizational pattern more often than developers who do not have access to the units of learning.

- H3: the organization of information generated by the social tool into units of learning helps the software developers to understand new knowledge more easily than developers who do not have access to the units of learning.

2) Selection of Participants: the participants who collaborated in this experiment were computer science undergraduate students.

The participants are individuals who have been specially selected from the population of interest to conduct the experiment.

Furthermore, the experiment wants simulating the individuals' behavior within an enterprise software development. Thus, the group of participants has to be homogeneous, so that participants must be able to perform the tasks proposed in a similar time.

To select the participants a Participant Profile Questionnaire ${ }^{1}$ was applied, attempting to identify students with the characteristics of a Java junior programmer. For this experiment, it was established that a junior programmer is a person who has less than 4 years of experience in object-oriented programming and basic to

1 https://docs.google.com/a/uenp.edu.br/spreadsheet/viewform?formkey=dE1SS2Et N251 cmRPX0 9yeHhDRURrYXc6MQ 
intermediate knowledge of software architecture, design patterns, organization and good coding practices.

From a group of seventy students, nine participants were selected. The sample represents a homogeneous software development team. All were male and between 20 and 25 years old. One of the students performed the pilot experiment, and the other eight actively participated in the experiment.

3) Description of the Experiment: In this experiment, we want to evaluate whether the proposed approach can improve the organizational learning, through the observation of real tasks performed by the participants. The participants were asked to perform two maintenances on existing software. The software is a system for the management of course work completion, developed in Java for the desktop platform and has simple 3-tier architecture.

The two proposed maintenances were applications of design patterns. In the first maintenance, the participants were asked to improve the classes that manage data persistence, applying the Data Access Object (DAO) pattern. However, this maintenance was divided into two tasks:

- Applying the DAO pattern using the Generic DAO in the student, teacher, area, employee and person classes that have the same data persistence methods.

- Applying the Factory pattern together with Generic DAO, in case of changes to the DBMS, since the Generic DAO pattern was applied specifically to Postgres connections.

The second maintenance was applied in the persistence layer. The participants were asked to apply the Singleton pattern in the class responsible for creating the connection to DBMS. They were then asked to modify the project, applying the Factory Method pattern. Thus, the second maintenance was divided into two tasks:

- Applying the Singleton pattern in the class responsible for creating the connection to DBMS, ensuring that there is only one instance of this class.

- Adapting to the Singleton pattern, implemented prior to the Factory Method pattern, creating a factory for connections to multiple DBMSs.

Consequently, each of the maintenances was divided into two tasks, and it was necessary to perform both tasks to complete each maintenance. From this, using the approach of Fig. 2, an expert developed units of learning, as content packages, to help the participants to perform each of the maintenances.

The expert that generated the units of learning conducted the entire experiment and took notes about it. Furthermore, each participant performed the two maintenances, and after completing each task, they answered a questionnaire to explain their opinion of the task.

4) Description of Analysis: the analysis of this experiment was conducted using qualitative analysis. The qualitative study is related to research on objects when the results are presented in natural terms (Seaman, 1999).

The analysis was realized using discursive textual analysis (Moraes and Galiazzi, 2006). This analysis is recommended for qualitative research, and this methodology shares many of the assumptions evident in other methodologies that also 
belong to the field of textual analysis, such as content analysis (Bardin, 1977) and discourse analysis (Pêcheux, 1995).

To execute the analysis, in order to answer the hypotheses proposed in section C-1), two questionnaires (shown in Table 1 and 2) were answered by the participants in the experiment. Table 1 shows the questions applied to participants who had access to content package and Table 2 shows the questions applied to participants who did not have access to content package. Moreover, the notes made by experts observing the execution of experiments were also used.In content analysis, the research objectives are defined by the researcher, explaining the contexts that she/he wishes to analyze. Thus, the first step of the analysis is to define the categories, which are units of general context, setting limits to perform the analysis

Table 1

Questionnaire applied at the end of the task - using content package

\begin{tabular}{|c|c|}
\hline Question & Description \\
\hline QA1 & Which is your group? \\
\hline QA2 & Which is the task performed? \\
\hline QA3 & What time did you start performing the task? \\
\hline QA4 & What time did you finish performing the task? \\
\hline QA5 & Have you ever implemented the proposed pattern to solve the task? \\
\hline QA6 & Did you have any difficulties while performing the task? If so, describe them. \\
\hline QA7 & $\begin{array}{l}\text { Do you believe that the use of content package helped you to solve the task? } \\
\text { Give more details. }\end{array}$ \\
\hline QA8 & Was the organization of the material adequate? Give more details. \\
\hline QA9 & $\begin{array}{l}\text { Did the content package have all the contents required to solve the task? Give } \\
\text { more details. }\end{array}$ \\
\hline QA10 & $\begin{array}{l}\text { Do you believe that content package helped you to solve the task? Give more } \\
\text { details. }\end{array}$ \\
\hline QA11 & $\begin{array}{l}\text { Was there a specific content inside the content package that was most } \\
\text { important to solve the task? Give more details. }\end{array}$ \\
\hline QA12 & Please use this space to supply any further information you consider relevant. \\
\hline
\end{tabular}

Table 2

Questionnaire applied at the end of the task - not using content package

\begin{tabular}{ll}
\hline Question & Description \\
\hline QB1 & Which is your group? \\
QB2 & Which is the task performed? \\
QB3 & What time did you start performing the task? \\
QB4 & What time did you finish performing the task? \\
QB5 & Have you ever implemented the proposed pattern to solve the task? \\
QB6 & Did you have some difficulty to perform the task? Describe about it. \\
QB7 & Did you find materials that helped you to solve the task? What kind of web \\
& pages did these materials have? Give more details. \\
QB8 & Please use this space to supply any further information you consider relevant.
\end{tabular}


(Moraes and Galiazzi, 2006). Each category generally contains several units of analyzes, which is the unitary element content to be further submitted to classification (Moraes and Galiazzi, 2006). Therefore, the units of analysis are the entities that are analyzed in the study.

Thus, the general structure of discursive textual analysis is shown in Fig. 4, which presents nine units of analysis organized into two categories.

Thereafter, the questionnaires answered by the participants were studied, along with the expert's notes. To facilitate the understanding of the text analysis, the following symbolic identifiers were used:

- G1, G2: to identify which group the participant belongs to;

- P1, P2, .., P8: to identify the participant that answered the question;

- TA, TB, TC, TD: to identify the task;

- QA1, QA2, QA3, ..., QA12: to identify the questions in the questionnaire and applied upon completion of the task (using content package); and

- QB1, QB2, QB3, .., QB8: to identify the questions in the questionnaire applied upon completion of the task (without using content).

\section{Execution}

As mentioned above, each maintenance was divided into two tasks, resulting in two maintenances and four tasks, called A, B, C and D. During tasks A, B and C the participants had no prior knowledge to conduct them, and during the task $\mathrm{D}$ the participants had already performed a similar task. Three experts classified each task as easy or moderate.

The eight selected participants were divided into two groups, G1 and G2, so that, a balanced experiment was created, with two homogenous development teams. Therefore, the experimental method applied was a replicated study (controlled experiment) with two treatments: participants using the content packages and participants not using the content

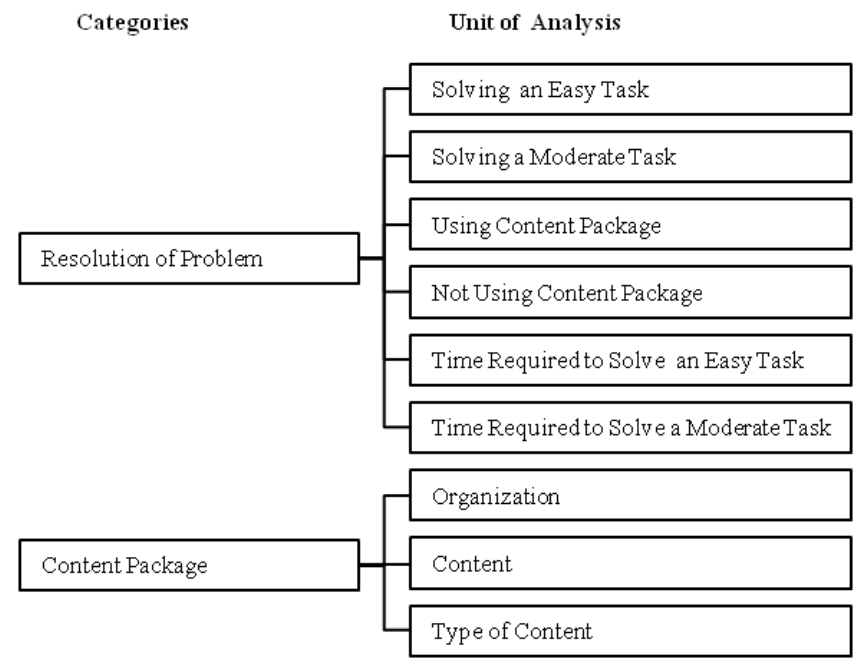

Fig. 4. General structure of discursive textual analysis. 
packages, all performing the same task. The experiment was executed four times, each one with a member from each group. The experiment was conduct in this way to facilitate the observation of the expert. Table 3 summarizes the experiment. During the execution of tasks, all participants had access to the Internet to search for material that could help them to solve the tasks.

After completing each task, the participants answered a questionnaire. Participants who had access to content package answered the Questionnaire applied at the end of the task - using content package (Table 1) and the participants who did not have access to the content package answered the Questionnaire applied at the end of the task - without using content package (Table 2).

In the following sections the results are given of the textual analysis for each category and unit of analysis presented in Fig. 4, based on 32 responses from 2 questionnaires and notes from experts.

\section{Results}

In this section, the main findings following analysis of each category and the units of analysis are presented. For each unit of analysis, the answered questions or expert notes related to the unit were analyzed, exploring the main ideas in the text, in order to answer a question proposed by the unit of analysis.

\section{A. Resolution of Problem}

The first category analyzed was the Resolution of Problem. The results of each unit of analysis in this category are described below.

1) Solving an Easy Task: the purpose of this unit is to answer the question: Did the participants correctly solve the proposed easy tasks? The analysis of this unit was done based on expert notes. An analysis was made regarding whether the task solution was implemented in the expected way, since there are many ways to imple-

Table 3

Overview of maintenance and task performed

\begin{tabular}{lllll}
\hline Maintenance & Task & Complexity & Group & $\begin{array}{l}\text { Access to Content } \\
\text { Package }\end{array}$ \\
\hline 1 & A & Easy & G1 & Yes \\
& & & G2 & No \\
& B & Moderate & G1 & Yes \\
& & & G2 & No \\
& C & Easy & G1 & No \\
& & & G2 & Yes \\
& D & Moderate & G1 & No \\
& & G2 & Yes \\
\hline
\end{tabular}


ment a pattern design. Therefore, an organizational pattern was set for each task, and this pattern was how the task was expected to be performed.

Considering the easy tasks, in which participants had access to the content package, $87 \%$ of the implementations were performed in the expected pattern. In relation to the participants who did not have access to the content package, $75 \%$ of the implementations were carried out in the expected way.

2) Solving a Moderate Task: the purpose of this unit is to answer the question: Did the participants correctly solve the proposed moderate tasks? For moderate tasks, in which participants had access to the content package, all implementations were performed in the expected pattern. For participants who did not have access, $37.5 \%$ of the implementations were carried out as expected.

3) Using Content Package: The purpose of this unit is to answer the question: What impact did the use of the content package have on solving the task?. This analysis was done using QA6 and QA7. All participants with access to the content package reported that it helped them to complete the task, but $50 \%$ of them still experienced difficulty. The difficulty was basically because they had never applied the required pattern. Some answers that stood out included the following statements:

- "First, I've had difficulty in assimilating knowledge, because I've never heard about it, and had no idea how to implement" (QA6, P4, G1, TA).

- "The greatest difficulty was that I have never used the pattern before and don't know how to use it very well" (QA6, P6, G2, TC).

4) Not Using Content Package: the purpose of this unit is to answer the question: How did the available resources, without being organized as units of learning, affect the resolution of tasks? This analysis was done using QB6 and QB7. 50\% of the participants reported no problems in solving the task, whereas the other $50 \%$ reported having difficulty performing the task. The difficulty was basically because they had never applied the required pattern. Another problem was the difficulty in finding good examples that could be easily used in the project. Some answers that stood out include:

- "There were several materials. Each only reported on what was improved, while others provide code examples, but each site had a different example" (QB7, P4, G1, TC).

- "Lack of prior knowledge required. Lack of understanding of simple educational materials, organized into stages" (QB7, P7,G2,TA).

Furthermore, it was reported that the main sites used to help solve the problems were wikis and forums.

5) Time required to solve an Easy Task: the purpose of this unit is to answer the question: Is there a difference in the time taken to solve easy tasks between developers who had access to the units of learning and those who did not have? The analysis was conducted using QA3, QA4, QB3 and QB4. There was a significant difference in the length of time taken to solve the task by the participants who had access to the content package and those who did not. 
The average time to perform Task A was 54 minutes for participants who had access to content package, and 108 minutes for participants who did not have access. This result demonstrates a difference of $100 \%$.

Task C, for participants who had access to the content package, was performed in 26 minutes on average, and for those who had no access, it was performed in 33 minutes on average, a difference of $23 \%$.

Therefore, the total time to perform both easy tasks was 80 minutes, for those who had access to content package, against 141 minutes for those who did not have access, a difference of $76 \%$.

6) Time Required to solve a Moderate Task: the purpose of this unit is to answer the question: Is there a difference in the length of time taken to solve moderate tasks between developers who had access to the units of learning and those who did not? The analysis of this unit was done using questions QA3, QA4, QB3 and QB4. Two moderate tasks were prepared. For the first, none of the participants had already implemented the proposed pattern. In contrast, for the second task they had already implemented the proposed pattern.

The average time taken to perform Task B was 55 minutes for participants who had access to content package, and 73 minutes for participants who did not have access. This result demonstrates a difference of $46 \%$.

Task D, for participants who had access to the content package, was performed in 37 minutes on average, and for those who had no access, it was performed in 25 minutes on average, a difference of $48 \%$. Unlike the other tasks, when it came to Task D, as the participants had already performed a task using the same pattern, those who did not have access to the content package performed more quickly.

\section{B. Content Package}

This category aims to analyze whether the content package was well built to help the participants to perform the tasks. For this purpose, three units of analysis were defined: Organization, Content, and Content Type.

1) Organization: the purpose of this unit is to answer the question: Was the content of the content package well organized? This question was analyzed using QA8. All participants in the experiment with access to the content package, reported that the organization was adequate, facilitating the understanding of content and therefore helping to solve the tasks.

2) Content: the purpose of this unit is to answer the question: Did the content package have all the content required to solve the task? This question was analyzed using QA9. All participants of the experiment with access to the content package claimed that the content package had all the contents needed to enable the performance of the proposed task.

3) Content Type: the purpose of this unit is to answer the question: What kind of material in the content package was important for solving the tasks? This question was analyzed using QA10 and QA11. In relation to the type of content that helped the participants to solve the task, the example of code source is the material that was most mentioned. However, several participants reported there is not a specific 
single type of material that helped, but rather the well-organized set of materials that was essential to carrying out the tasks. The answers that stood out include the following statements:

- "....the way the material was laid out facilitated the organization of ideas and the development of the proposed work." (QA10, P3, G1, TA);

- "There is no single type of material that helped. It was the well-organized set of materials. "(QA10, P1, G1, TA).

\section{Discussion}

This paper presents an approach for the semi-automatic generation of units of learning from content inserted into a social tool in order to organize this content didactically by an expert, to promote organizational learning within software development companies. In order to analyze the feasibility of this approach, three hypotheses were defined and an experiment was conducted for the purpose of proving or refuting the hypotheses.

An analysis of the results found that the time taken to solve a task, using the unit of learning was less than the time to solve the same task without using unit of learning. Fig. 5 shows the average time in minutes to solve each task. In three of the four tasks the average time was less for participants with access to the unit of learning. Only in Task D did the participants without access perform the task in a shorter time. However, Task D was the only task in which the participants had already performed a similar task.

Thus, this approach is efficient mainly when working with new knowledge, i.e., the acquirement of new knowledge is faster. Therefore, based on this experiment, Hypothesis $\mathrm{H} 1$ is true.

Another important point is how the tasks were performed. In the experiment, the proposed tasks were often not implemented as expected. This may have been due to a misunderstanding of the requirements or different ways of implementing the same task. Fig. 6 shows the percentage of tasks performed as expected.

The number of tasks implemented, as expected, was higher or equal for those participants who had access to units of learning. Fig. 6 shows that the largest differences were in Tasks B and D, which were the most complex. Therefore, although participants who did not have access to the unit of learning performed Task D more quickly than participants who had access to content package, in $50 \%$ of these cases they performed the task in a way that was not expected.

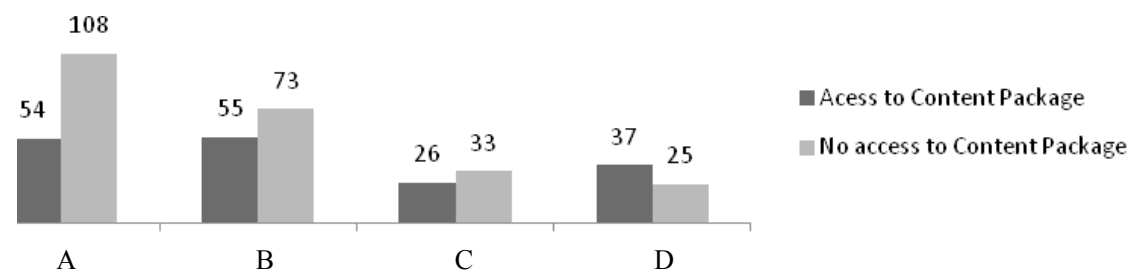

Fig. 5. Time in minutes to solve each task. 


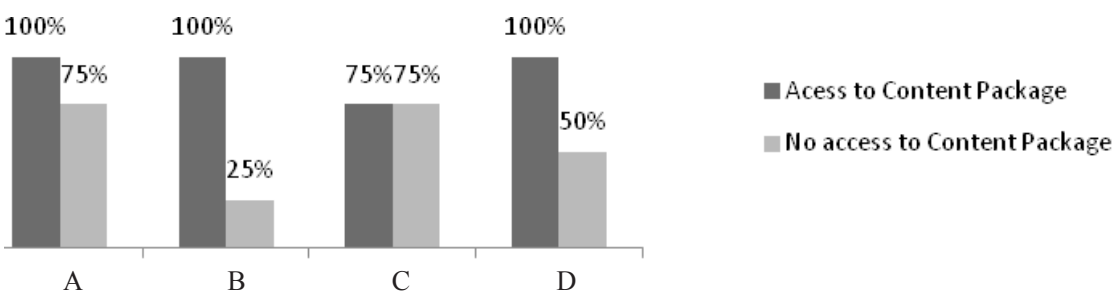

Fig. 6. Percentage of tasks performed as expected.

Therefore, based on this experiment, it is judged that the Hypothesis $\mathrm{H} 2$ is true. Consequently, the approach is efficient to help developers to implement tasks using organizational patterns. Furthermore, a common problem that occurs in companies is the reinvention of the solution and the repetition of errors (Tiwana, 2002). Therefore, the proposed approach can help to minimize this problem, transferring the best practices and knowledge.

To analyze the third hypothesis, the first step was to analyze the difficulty of the participants to assimilate the knowledge. From these data it is not possible assert that the Hypothesis $\mathrm{H} 3$ is true, as $50 \%$ of the participants with access to the unit of learning reported that they experienced difficulty to assimilate the knowledge, the same rate of those who did not have access to the unit of learning.

However, if it is considered that those who had access to the units of learning solved the tasks involving new knowledge faster and using the expected pattern, so it can be inferred that they assimilated the knowledge better than those who did not have access. Therefore, subsequently according to the experiment, the Hypothesis H3 is true. Thus, it can be surmised that the organization of various materials into a course set by an expert can help software developers to understand better the problem to be solved, as well as perform the proposed tasks faster and more accurately.

Furthermore, the expert notes show that the participants who did not have access to the units of learning, in some cases, even accessing the same material present in the unit of learning, did not understand the content or were unsure if it was the correct solution or the best solution to the problem. This is because the information was not contextualized and organized by an expert, as were the units of learning.

Moreover, the use of this approach can help to mitigate a kind of problem that is very common in companies in a knowledge-intensive field, such as software engineering. This problem is unrecognized knowledge. This is when companies do not know what they already know. As a result, they normally reinvent and fail to apply existing knowledge (Tiwana, 2002).

Furthermore, the use of the proposed approach can motivate team members to generate documents, improving the coding of knowledge and assisting in the acquisition of organizational knowledge. Topics mapped on learning design schema and needed to generate the learning units may not exist in the knowledge base. This might facilitate the identification of missing content, motivating members to create these contents.

Hence, the experiment confirms that the organization of information into units of learning helped the participants to perform the tasks because the material was clearly 
organized, with concise logic, facilitating the organization of ideas. However, the approach will be effective only if there is appropriate content generated by social tools, as well as, the learning design schema having to be generated by domain experts. For this, the expert should know not only the domain but also the needs of those who will use the units of learning.

\section{Conclusions and Future Works}

The work presented here focuses on the creation of units of learning from content inserted into social tools with the purpose of organizing knowledge in order to facilitate its reuse. This is necessary because these tools increasingly enhance the way people communicate, but often do not care how the knowledge they generate is used.

The use of collaborative tools is a trend in software development companies. The use of such tools, which aids the creation of knowledge, mainly through social learning, is growing quickly and provides important resources that can enhance organizational learning. However, the organization of knowledge can be improved. To do this, this study proposes organizing the content into learning objects and subsequently into units of learning. As a result, a logical sequence of contents can be created, which can facilitate learning from contents generated within a company, increasing the organizational learning.

To validate the approach, an experiment was proposed to evaluate how the units of learning can help software development, focusing on improvements in existing software. Pages from Wikipedia and a private wiki were extracted and organized into learning objects. From these objects units of learning were generated. These units have the content and sequence defined by a domain expert, and they were formatted as a content package.

The experiment was an experimental method, which aims to collect data in a controlled environment, to confirm the three hypotheses. Thus, the experimental method applied was a replicated study with two treatments: participants using the content package and participants not using content package, all performing the same task.

After applying the experiment, it was concluded that the hypotheses are true, and through this approach, knowledge can be better organized, helping software developers understand the problem to be solved faster and better, as well performing the proposed tasks easily and efficiently.

Furthermore, this approach is efficient mainly in the acquisition of new knowledge and to avoid unrecognized knowledge. The approach is also an efficient way of helping the developer to implement a task using an organizational pattern, and can minimize reinvention of the solution and the repetition of errors. All this is possible, as long as the learning design schema is well designed by an expert, and the knowledge repository contains all the contents required to generate the learning objects and units of learning.

For future research, we propose reducing the intervention of experts in the generation of units of learning and implementing the proposed approach in an environment based on wikis and social networking. 


\section{Acknowledgements}

This work is being developed with the financial support of Fundação Araucária (Foundation in Support of the Scientific and Technological Development of the State of Paraná, Brazil).

\section{References}

Ali, I.M., Pascoe, C., Warne, L. (2002). Interations of organization culture and collaboration in working and learning. Education Technology and Society, 5(2).

Amorim, R.R. , Lama, M., Sánchez, E., Riera, A., Vila, X.A. (2006). A Learning Design Ontology based on the IMS Specification. Educational Technology \& Society, 9, 38-57.

Bardin. L. (1977). L' analyse de contenu.Presses universitaires de France, France.

Basili V. (1996). The Role of Experimentation in Software Engineering: Past, Present, Future. Proc. of the 18th International Conference on Software Engineering, 1(2), 133-164.

Capuano, N., Gaeta, M., Orciuoli, F., Ritrovato, P. (2010). Semantic Web Fostering Enterprise 2.0. Proc. International Conference on Complex, Intelligent and Software Intensive Systems, 1087-1092.

Carreras, M., Pérez, M., Bernabé, B., Calero, A., Pérez, M., Skarmet, G. (2011). Towards a Semantic-Aware Collaborative Working Environment. Computing and Informatics, 30 ( 1), 7-30.

Dantas, J.R.V., Farias, P.P.M. (2010). Conceptual navigation in knowledge management environments using NavCon. Information Processing \& Management, 46, (4), 413-425.

Davenport, T.H., Prusak, L. (1998) Working Knowledge: How Organizations Manage What They Know. Harvard Business School Press, Boston.

Hadjerrouit, S. (2012). Investigating Technical and Pedagogical Usability Issues of Collaborative Learning with Wikis. Informatics in Education, 11(1), 45-64.

IEEE (2002). IEEE Draft Standard for Learning Object Metadata. IEEE-SA Standard 1484.12.1.

IMS (2004). IMS Content Packaging Information Model, Version 1.1.4, IMS Global Learning. Retrieved from http://www.imsglobal.org/content/packaging/cpvlp1p2/imscp_infovlplp2.html.

IMS (2003). IMS Learning Design Information Model, Version 1.0 Final Specification. Retrieved from http://www.imsglobal.org/learningdesign/ldvlp0/imsld_infov1p0.html.

Koper, R., Olivier, B., St.B.D., Ab.B. (2004). Representing the Learning Design of Units of Learning. Educational Technology \& Society, 7, 97-111.

Leung, W.E.C., Li, Q. (2007). An Experimental Study of a Personalized Learning Environment Through OpenSource Software Tools. IEEE Transactions On Education, 50(4), 331-337.

Lykourentzou, I., Papadaki, K., Vergados, D.J., Polemi, D., Loumos, V. (2010). CorpWiki: A self-regulating wiki to promote corporate collective intelligence through expert peer matching. Information Sciences, 180(1), $18-38$.

McAfee, A.E. (2006). Enterprise 2.0: The Dawn of Emergent Collaboration. MIT Sloan Management Review, 47(3).

Menolli, A.L. Malucelli, A., Reinehr, S. (2011) Towards a Semantic Social Collaborative Environment for Organizational Learning. Proc. International Conference on Information Technology and Applications (ICITA 2011), IEEE Press, 65-70.

Menolli, A.L., Reinehr., S., Malucelli, A. (2012a). Social Learning: Defining Learning Objects from Social Tools. Proc. of International Conference WWW/Internet (ICWI), 101-108.

Menolli, A.L., Reinehr., S., Malucelli, A. (2012b). Ontology for Organizational Learning Objects based on LOM Standard. Proc. of the Latin American Conference en Informática (CLEI), Colombia.

Moraes R., Galiazzi, M.C. (2006). Discursive textual analysis: a multiple face recontructive process. Ciência \& Educação, 12(1), 117-128.

Pêcheux. M. (1995). Automatic Discourse Analysis.Rodopi, Amsterdan.

Polsani, P.R. (2004). Use and abuse of reusable learning objects. Journal of Digital information, 3(4).

Sambamurthy, V., Bharadwaj, A., Grover, V. Shaping. (2003). Agility through Digital Options: Reconceptualizing the Role of Information Technology in Contemporary Firms. MIS Quarterly, 27(2), 237-263.

Seaman, C. (1999). Qualitative Methods in Empirical Studies of Software Engineering, IEEE Computer, 25(4), $557-572$. 
Senge, P., Kleiner, A., Roberts, C., Ross, R., Smith, B.J. (1994). The fifth discipline field book. New York, Doubleday.

Takeishi A. (2002). Knowledge Partitioning in the Interfirm Division of Labor: The Case of Automotive Product Development. Organization Science, 13(3), 321-338.

Teece, D.J., Pisano, G., Shuen, A. (1997). A Dynamic Capabilities and Strategic Management. Strategic Management Journal, 18(7), 509-533.

Tiwana. T. (2002). Knowledge Management Toolkit. Person Education, 2 ed.

Tseng, S.M., Huang, J.S. (2011). The correlation between Wikipedia and knowledge sharing on job performance. Expert Systems with Applications, 38(5), 6118-6124.

Vassileva, J. (2009) Toward social learning environments. IEEE Transactions on Learning Technologies, 1(4), $199-214$.

Zouq, A., Nkambou, R. (2009) Enhancing Learning Objects with an Ontology-Based Memory. (2009). IEEE Transactions on Knowledge and Data Engineering, 21(6), 881-893.

A.L.A. Menolli is a PhD student at Postgraduate Program in Computer Science (PPGIa) at Pontifical Catholic University of Paraná (PUC-PR), Brazil. ME in computer science at State University of Maringá (UEM). Currently, he is an assistant professor at State University of North of Paraná (UENP). He has experience in computer science, with emphasis on software engineering, acting on the following topics: organizational learning, business intelligence, ontology, web semantic and data warehouse.

S. Reinehr received her $\mathrm{PhD}$ in Engineering from Universidade de São Paulo (Brazil). She is currently Director of Continuing Education and Associate Professor in the Postgraduate Program on Informatics at Pontifical Catholic University of Paraná in Brazil. Her research interests include software engineering, software quality, software process improvement, service management, IT project and portfolio management, software reuse and IT metrics.

A. Malucelli received her PhD in Electrical and Computer Engineering from Faculty of Engineering at University of Porto in Portugal. She is currently an Associate Professor in the Postgraduate Program on Informatics at Pontifical Catholic University of Paraná in Brazil. Her research interests include software engineering, ontologies, multi-agent systems and information systems in healthcare.

\title{
Organizacinio mokymosi tobulinimas: mokymosi vienetų sudarymas remiantis socialinėmis interneto priemonėmis
}

\author{
André Luís Andrade MENOLLI, Sheila REINEHR, Andreia MALUCELLI
}

\footnotetext{
Naujos technologijos - socialiniai tinklai, vikiai, tinklaraščiai ir kitos internetinio bendravimo priemonès - sudaro sąlygas bendradarbiavimu grịstam darbui ir yra svarbūs bendruomeninio mkymosi veiksniai. Daugelis įmonių naudoja šias priemones kaip pagrindą jų intraneto svetainėse. Vis dèlto šiomis priemonemis sugeneruojamas turinys dažnai nėra tinkamai sutvarkytas. Mokymosi objektai ir mokymosi vienetai yra dvi el. mokymosi sąvokos, ịgalinančios tvarkyti turinị nuoseklia seka, taip tobulinant jo pakartotinį naudojimą. Straipsnyje siūlomas mokymosi objektų ir mokymosi vienetų generavimo naudojant socialinius tinklus metodas, kuris palengvintų informacijos tvarkymą siekiant jos pakartotinio naudojimo. Siekiant įvertinti siūlomą metodą buvo atliktas eksperimentas ir diskursyvi tekstinè analizè. Rezultatai rodo, kad metodas yra veiksmingas tobulinant organizacini mokymąsi programinès įrangos kūrimo grupèse. Be to, šis metodas pagerina naujų žinių ịijimą, padeda prižiūrèti organizacinę tvarką ir sumažinti sprendimų keitimą bei klaidų pasikartojimą.
} 